\title{
DIFFERENTIAL TRAINING TASKS TRIGGER THE DECREASE OF CONCATENATION BETWEEN CARDIOVASCULAR PARAMETERS
}

\author{
Deivydas Velička ${ }^{1}$, Gilija Bernotienè ${ }^{1}$, Kristina Poderiené ${ }^{2}$, \\ Alfonsas Vainoras ${ }^{1}$, Jonas Poderys ${ }^{2}$ \\ Lithuanian University of Health Sciences ${ }^{1}$, Kaunas, Lithuania \\ Lithuanian Sports University', Kaunas, Lithuania
}

\begin{abstract}
Background. A lot of studies have shown the Differential Training (DT) is more effective than the traditional training based on repetition at constant conditions. The aim of this study was to find the changes in dynamical concatenation between ECG parameters during the DT task.

Methods. Participants (13 healthy adult males) performed two balance tests standing on LIBRA balance board. Continuous ECG registration during both balance tests and during the rest was 3 minutes. The changeable parametric interactions and its dynamics during exercise tasks while monitoring ECG parameters and its data sequences analysis based on mathematical method based on matrix theory were applied, the concatenation between ECG parameters were analysed.

Results. Results obtained during the study showed that there were no drastic differences between ECG parameters while performing both balance tests. The concatenation between analysed ECG parameters increased or there was no significant change. The decrease of concatenation was observed during the second task while the participants performed the squats standing on the balance board. This type of change in concatenation was found during the analysis of all ECG parameters, i.e. between duration of RR intervals and QRS, between JT and RR intervals and between QRS and JT intervals.

Conclusion. DT tasks trigger the decrease of concatenation between cardiovascular parameters that allows discussing about the hypothesis that decrease of concatenation between systemic regulatory commands and cardiac metabolic changes could be one of possible chain activating and enhancing the efficiency of long-term adaptation at conditions of DT.
\end{abstract}

Keywords: cardiovascular system, concatenation, Differential Training.

\section{INTRODUCTION}

$\mathrm{T}$ he discussion on schedule of the training session is an important research question. How to make motor learning and training more efficient and effective is important for sports practices as well. The application of variable practice has achieved acceptance as being beneficial for motor learning processes. Numerous studies have demonstrated enhanced motor learning performance in variable practice over repetitive learning schedules (Beckmann, 2013).
The new methodology of so called "Differential Learning" (DL) or "Differential Training" (DT) was introduced (Schöllhorn, 1999, 2000) and this approach has been applied in the context of motor learning and extensively investigated by Schöllhorn and collaborates (Frank, Michelbrink, Beckmann, \& Schöllhorn, 2008; Schöllhorn, Beckmann, Janssen, \& Drepper, 2010). It was shown that DT was more effective than traditional training (TT). DT scheduled on movement variations are from a 
traditional point of view considered as movement errors and accordingly have to be avoided in common motor learning schedules (Schöllhorn, 1999; Henz \& Schöllhorn, 2016). The effectiveness of DT was shown for track and field (Beckmann \& Gotzes, 2009; Beckmann \& Schöllhorn, 2006), handball (Wagner \& Müller, 2008), basketball (Lattwein, Henz, \& Schöllhorn, 2014), volleyball (Römer, Schöllhorn, Jaitner, \& Preiss, 2009), iceskating (Savelsbergh, Kamper, Rabius, De Koning, \& Schöllhorn, 2010), hockey (Beckmann, Winkel, \& Schöllhorn, 2010). Most intriguingly, DT not only leads to increased acquisition rates but also to increased learning rates (Beckmann \& Schöllhorn, 2006; Savelsbergh et al., 2010).

Internal body changes during exercising are a trigger for long-term adaptation (Saltin, \& Rowell, 1980; Boström et al., 2013; Alleman et al., 2015). A number of physiological changes can be described as activation of mechanisms responsible for maintaining of homeostasis. Thus, these changes are an important because this is a trigger for activation of long-term adaptation processes taking place in the body during the recovery process (Boström, Graham, \& Georgiadi, 2013).

Cardiovascular system is a vital body system and plays an important role in long-term adaptation to workloads. There are relatively small cardiovascular changes at onset of low intensity exercising and thus could be a good situation to vary by exercising tasks and compare dynamical concatenation between cardiovascular parameters. A lot of studies have shown that the Differential Training (DT) is more effective than the traditional training based on repetition at constant conditions. However, the underlying mechanisms are not fully understood. We hypothesised that the fine tuning between various body fractal levels is an important for sports performance and the disruption or the temporally loss of these interaction could be a trigger for long term adaptation. The aim of this study was to determine the changes in dynamical concatenation between ECG parameters during the DT task.

\section{METHODS}

Thirteen healthy adult male volunteers took part in this study. After adaptation to the laboratory environmental all participants performed two balance tests by standing on LIBRA balance board. The first balance task was without additional disturbances and during the second balance task the participant was asked to perform squats, i.e. in this task, while each next squat had to be performed at constantly changing conditions, which means that this situation was more close to the methodology of DT.

The continuous 12-lead ECG registration was done before and after each balance task. Continuous ECG registration during both balance tests and during the rest was 3 minutes. In this study the changeable parametric interactions and its dynamics during exercise tasks ECG parameters ( $R R$ intervals; JT intervals and duration $Q R S$ complex) monitoring and its data sequences analysis based on mathematical method based upon matrix theory were applied. According to the model of integral evaluation of body functioning during exercising the concatenation between the two chosen ECG parameters were analysed. Two synchronous signals (ECG parameters) were taken at discrete time intervals and after normalization (to interval $[0 ; 1]$ ) by the difference between maximal and minimal physiological values. The data was normalized using the formula

$$
x_{\text {new value }}=\frac{x_{\text {old value }}-x_{\min }}{x_{\max }-x_{\min }},
$$

where $x_{\min }$ and $x_{\max }$ are minimal and maximal physiological values of parameter.

These signals are co-integrated into the second order matrix. From the initial parameters of the matrix (difference dfr $A_{n}=x_{n}-y_{n}$ and co-diagonal product cdp $\mathrm{A}_{\mathrm{n}}=\mathrm{ab}\left(\mathrm{x}_{\mathrm{n}-1}-\mathrm{y}_{\mathrm{n}-1}\right)\left(\mathrm{x}_{\mathrm{n}+1}-\mathrm{y}_{\mathrm{n}+1}\right)$, in both cases $x_{n}$ and $y_{n}$ are real numbers and they represent the recorded parameters) follow characteristic which has more comprehensive sense, i.e. discriminant (Dsk):

$$
\text { Dsk } A_{n}=\left(\text { dfr }_{A_{n}}\right)^{2}+4 \operatorname{cdp} A_{n}
$$

Large Dsk values indicate low inter-parametric concatenation, whereas small Dsk values (close to zero) correspond to high interaction between the analysed parameters.

Statistical analysis. Kolmogorov-Smirnov test was used to determine whether data had an underlying normal distribution and the requirement for homogeneity variance of compared samples that was verified with Levene's test. The difference was regarded as statistically significant if $p<.05$. The values are reported as arithmetical mean \pm standard error of the mean (SEM). 


\section{RESULTS}

The results of this study were analysed on the basis of the statement that the complexity of a dynamic system decreases with the loss of parametric independence (Alleman, Stewart, Tsang, \& Brown, 2015). Research (Costa, Peng,
\& Goldberger, 2008) shows that the increase of concatenation between cardiovascular indices begins at the onset of exercise. This type of changes can be observed during some stages of workload but reaching some functional state

Table. ECG parameters registered during various parts of experiment

Note. Averaged data of 3 minutes during each part of experiment.

\begin{tabular}{|c|c|c|c|c|c|}
\hline Index & Before & $\begin{array}{c}\text { First balance } \\
\text { task }\end{array}$ & Rest & $\begin{array}{c}\text { Second } \\
\text { balance task }\end{array}$ & Rest \\
\hline $\begin{array}{c}\mathrm{HR} \\
\mathrm{b} / \mathrm{min}\end{array}$ & $77.8 \pm \mathbf{4 . 0}$ & $89.3 \pm 4.2$ & $81.5 \pm 4.2$ & $90.7 \pm 3.5$ & $83.7 \pm 4.4$ \\
\hline $\begin{array}{c}\mathrm{JT} \\
\mathrm{ms}\end{array}$ & $249.5 \pm 7.7$ & $235.7 \pm 7.9$ & $245.3 \pm 8.2$ & $234.6 \pm 6.7$ & $238.6 \pm 7.9$ \\
\hline $\begin{array}{c}\mathrm{QRS} \\
\mathrm{ms}\end{array}$ & $84.4 \pm 1.7$ & $85.7 \pm 2.1$ & $85.6 \pm 1.6$ & $87.8 \pm 2.0$ & $85.3 \pm 1.4$ \\
\hline
\end{tabular}

Figure 1. Concatenation between ECG parameters RR intervals \& duration of QRS

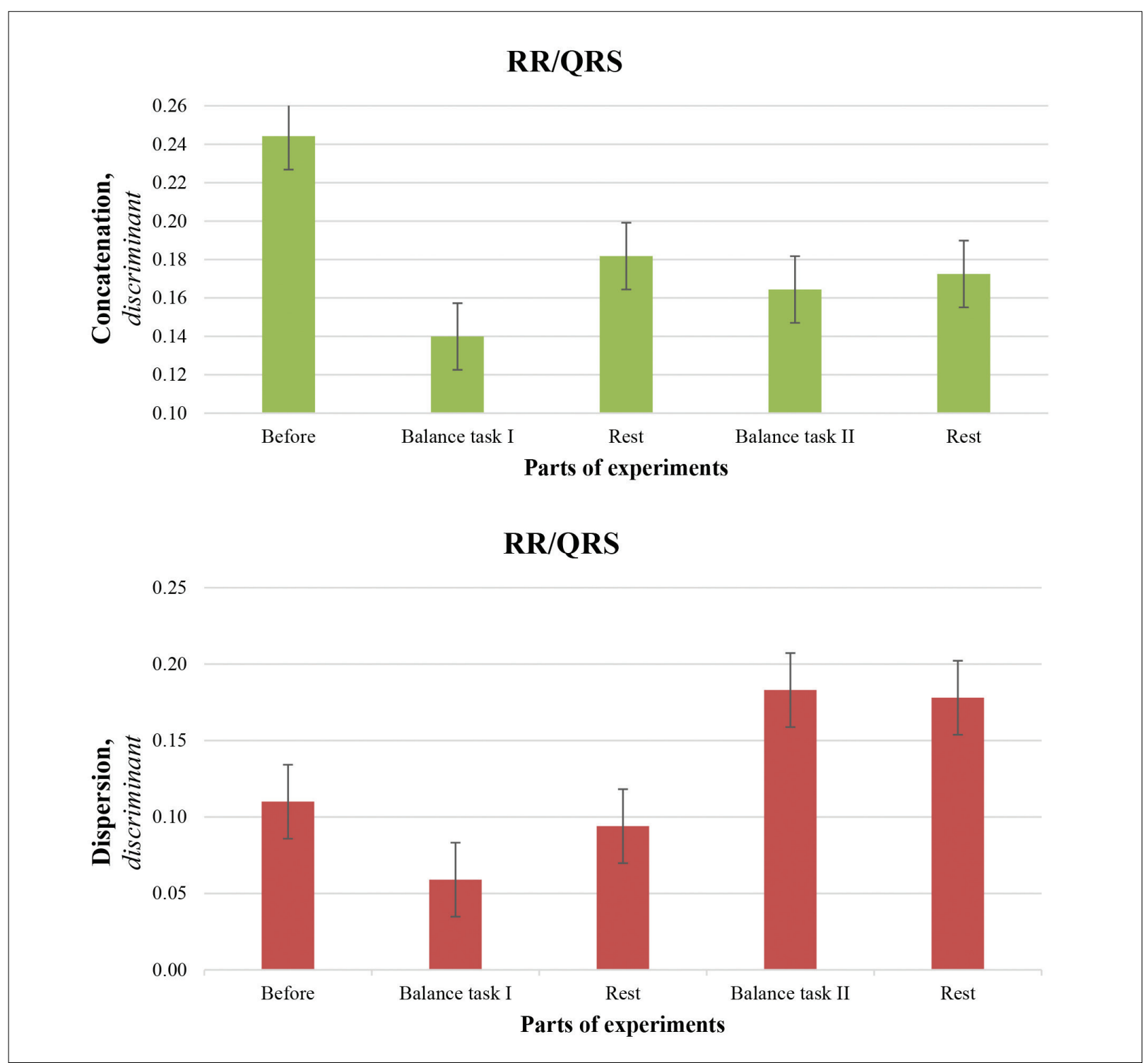

Note. According the model of integral evaluation (Vainoras, 2002) RR - represents systemic regulatory response; QRS represents organ level regulatory response. 
(fatigue) the increase of concatenation has changed in an opposite direction, i.e. the decrease or loss of these concatenations leads to inability to continue exercising.

Results obtained during the study showed that there was no drastic difference between the values of registered ECG parameters while performing both balance tests by standing on LIBRA balance board. The values of RR intervals were $0.93 \pm$ $0.04 \mathrm{~s}$ - before exercising; $0.85 \pm 0.03 \mathrm{~s}$ - during the first and $0.69 \pm 0.02 \mathrm{~s}-$ during the second exercise tasks. In the Table these data presented as HR values during various part of experiment. The results obtained during this study showed that even low intensity of exercising at constantly changing conditions triggers some changes between cardiovascular parameters.

Figures 1-3 present the data obtained during data sequences analysis based on mathematical method based on matrix theory. The increase of concatenation between systemic and organ level commands while exercising presented in Figure $1\left(\mathrm{D}_{\mathrm{RR} / \mathrm{QRS}}\right.$ was $0.24 \pm 0.01$ - before exercising and $\mathrm{D}_{\mathrm{RR} / \mathrm{QRS}}$ was $0.14 \pm 0.01$ and $0.16 \pm 0.01$ - during the first and second balance tasks). There were no significant changes in concatenation between parameters representing peripheral (organ) regulatory commands and metabolic changes (the initial values of $\mathrm{D}_{\mathrm{QRS} / \mathrm{TT}}$ was $0.28 \pm 0.01$; during the first balance task $0.27 \pm 0.01$ and $0.25 \pm 0.01$ - during the second task), these data presented in Figure 2. The concatenation between systemic regulatory commands and metabolic changes significantly $(p<.05)$ decreased, these data presented in Figure 3 . We should point that the increase of complication of the motor task lead to more expressed decrease of this concatenation, i.e. $\mathrm{D}_{\mathrm{RR} / \mathrm{T}}-0.13 \pm 0.05$ while performing the first balance task and $\mathrm{D}_{\mathrm{RR} / \mathrm{T}}$ was 0 . $16 \pm 0.06$ while performing the second balance task, i.e. the squats were performed at constantly changing conditions.

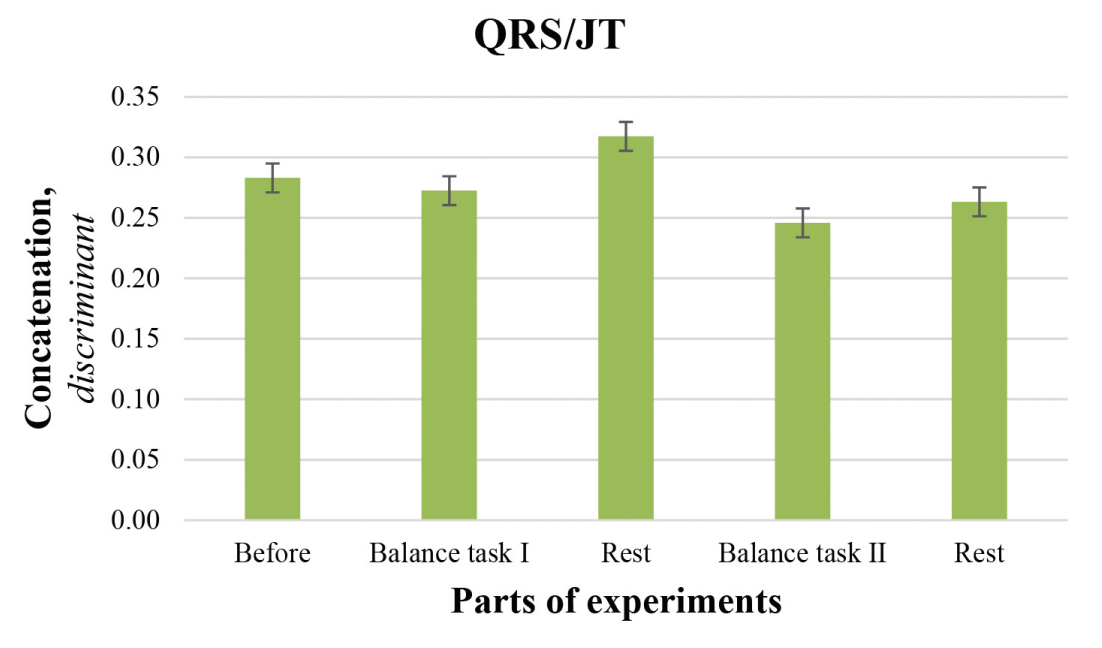

QRS/JT

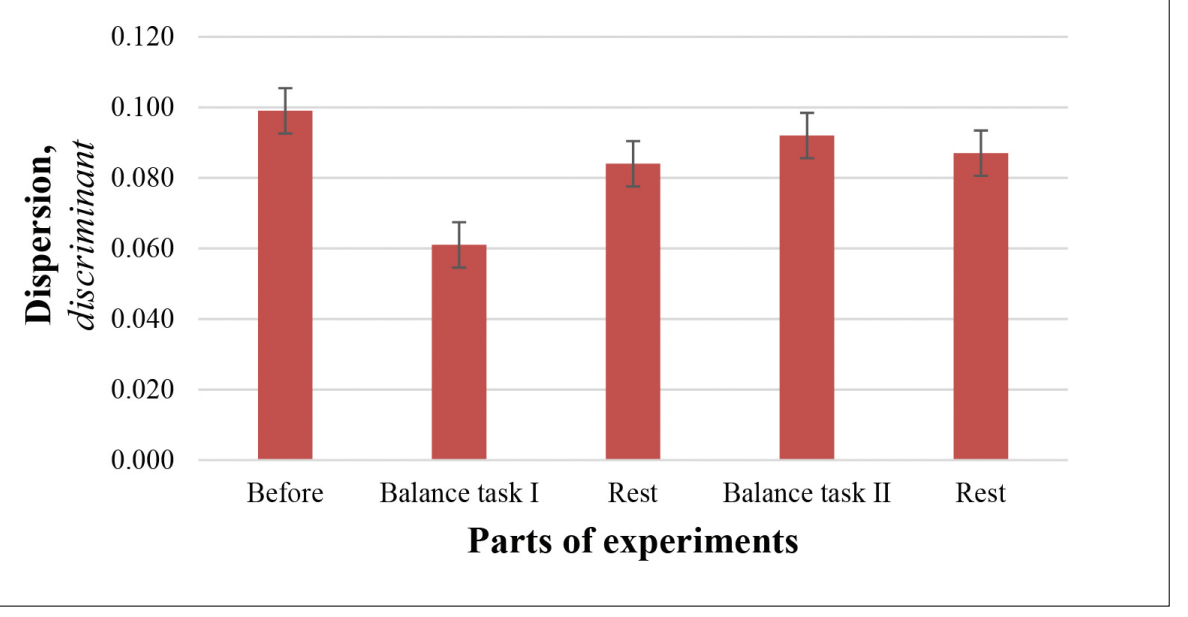

Figure 2. Concatenation between ECG parameters QRS duration \& JT interval
Note. According the model of integral evaluation (Vainoras, 2002) QRS - organ level regulatory response; JT represents cardiac metabolic response. 
Figure 3. Concatenation between ECG parameters RR \& JT intervals

Note. According the model of integral evaluation (Vainoras, 2002) RR - represents systemic regulatory response; JT represents cardiac metabolic response.

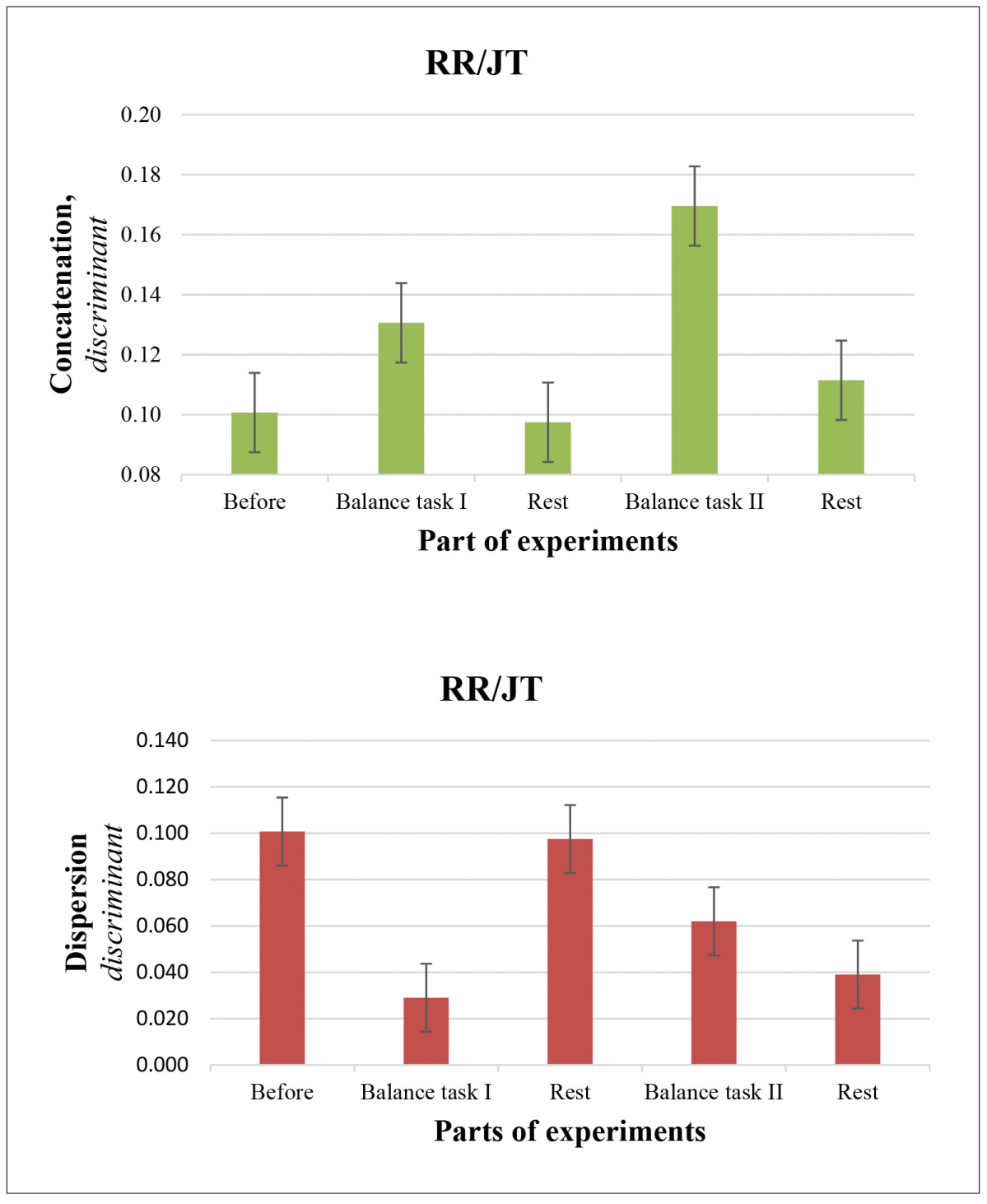

\section{DISCUSSION}

The task to keep balance while standing on balance board can be described as movement a variation that is closely to DT tasks. The second task, i.e. to perform the squats during the balance test while each next squat should be performed at constantly changing conditions, what means this situation was more complicated, more unexpected and both balance tasks laid in line with the requirements of the DT methodology.

Results obtained during the study showed that there were no drastic differences between the values of registered ECG parameters while performing both balance tests by standing on LIBRA balance board. The significant difference in the type of change of concatenation between registered ECG indices was distinguished. The concatenation between analysed ECG parameters increased or there was no significant change while performing the balance task by standing on LIBRA balance board only. The decrease of concatenation was observed during the second task while the participants performed the squats standing on the balance board. This type of change in concatenation was found during the analysis of all ECG parameters, i.e. between duration of RR intervals and QRS; between JT and RR intervals and between QRS and JT intervals.

A dynamical concatenation shows the interactions of components and changes of their interconnections (Bikulčienè, Navickas, Vainoras, Poderys, \& Ruseckas, 2009; Poderys et al., 2015). According the model of integral evaluation 
(Vainoras, 2002) dynamical concatenation $\mathrm{D}_{\mathrm{RR} /}$ QRS describes intersystemic concatenation between two fractal levels, i.e. the link between responses of systemic and organ levels; $\mathrm{D}_{\mathrm{RR} / \mathrm{T}}$ describes relationship between regulatory and supplying systems (metabolic response) and $\mathrm{D}_{\mathrm{JT} / \mathrm{QRS}}$ describes relationship between organ level regulatory response and cardiac metabolic response (Vainoras, 2002; Telatavičienè, 2014).

Internal body changes occurred during exercising is a trigger for long-term adaptation. Mobilization of cardiovascular system during exercise tasks is warranted that the body meets the demands of exercising muscles. Aside from matching changes in ECG exercise also induces preconditioning whereby the body is more resistant even long after the exercise has ceased. So the physiological changes occurred during exercising are important trigger activating the long-term adaptation processes taking place in the body during the recovery process. All physiological systems undergo specific adaptations that increase the body's efficiency and capacity. The magnitude of these changes depends largely not only on the intensity and duration of the training sessions but on the content, i.e. on the type of motor tasks, as well.

A lot of evidence showing that DT is more effective than TT may be is that in repetitive training the training processes are stimulated less than in DL (Henz \& Schöllhorn, 2016). One line of argumentation might be that due to repetitive movement performance habituation processes of the cognitive and motor system are to be postulated (Henz \& Schöllhorn, 2016). However, the underlying mechanisms are not fully understood, and there is currently much focus on detailing such pathways (Boström et al., 2013).

In contrast, in repetition based motor learning movements are performed with a large number of repetitions without voluntary variations until a predefined ideal state of movement is reached. The system dynamic approach states that living systems show fluctuations continuously and an increase of fluctuations before a phase transition has the purpose to find a new and more effective mode. Within the DT approach, fluctuations during the motor learning process are a fundamental basis for improvement (Henz \& Schöllhorn, 2016).

\section{CONCLUSION}

Differential training tasks trigger the decrease of concatenation between cardiovascular parameters, that allows to discuss about the hypothesis that decrease of concatenation between systemic regulatory commands and cardiac metabolic changes could be one of possible chain activating and enhancing the efficiency of longterm adaptation at conditions of differential training.

\section{REFERENCES}

Alleman, R.J., Stewart, L.M., Tsang, A.M., \& Brown, D.A. (2015). Why does exercise "trigger" adaptive protective responses in the heart? Dose Response, 13(1). doi: 10.2203/dose-responsel

Beckmann, H., \& Gotzes, D. (2009). Differenzielles lehren und lernen in der leichtathletik. Sportunterricht, 58, 46-50. [DL teaching and learning in track and field]. Physical Education, 58, 46-50.

Beckmann, H., \& Schöllhorn, W. I. (2006). Differenzielles Lernen im Kugelstoßen. Leistungssport 36, 44-50. [Differential training in shot put]. Competitive Sports, 36, 44-50.

Beckmann, H. (2013). Untersuchung der Auswirkungen verschiedener Variationsbereiche des differenziellen Lernens und Lehrens im weiten Sinn auf ausgewählte technische Grundfertigkeiten im Hallenhockey. [Examination on effects of different variations in differential learning and teaching on selected techniques in hockey]. PhD thesis. Johannes-Gutenberg Universitët,
Mainz. Retrieved from http://ubm.opus.hbz-nrw.de/ volltexte/2013/3606

Beckmann, H., Winkel, C., \& Schöllhorn, W. I. (2010). Optimal range of variation in hockey technique training. International Journal of Sports Psychology, 41, 5-10.

Bikulčienė, L., Navickas, Z., Vainoras, A., Poderys, J., \& Ruseckas, R. (2009). Matrix analysis of human physiologic data. Proceedings of International Conference on Information Technology Interfaces (pp. 41-46). University of Zagreb.

Boström, P. A, Graham, E. L., Georgiadi, A., \& Ma, X. (2013).Impact of exercise on muscle and non-muscle organs. IUBMB Life, 65(10), 845-50. doi: 10.1002/ iub. 1209

Costa, M. D., Peng, C. K., \& Goldberger, A. L. (2008) Multiscale Analysis of Heart Rate Dynamics: Entropy and Time Irreversibility Measures. Cardiovascular Engineering, 8, 88-93. 
Frank, T. D., Michelbrink, M., Beckmann, H., \& Schöllhorn, W. I. (2008). A quantitative dynamical systems approach to differential learning: Selforganization principle and order parameter equations. Biological Cybernetics, 98, 19-31. 10.1007/s00422007-0193-x

Henz, D., \& Schöllhorn, W. (2016). Differential Training facilitates early consolidation in motor learning. Frontiers in Behavioral Neuroscience, 21(10), 199. doi: 10.3389/fnbeh.2016.00199

Lattwein, M., Henz, D., \& Schöllhorn, W. I. (2014). Differential training as an intervention strategy to prevent choking under pressure in basketball free-throw. In Book of Abstracts of the 19th Annual Congress of the European College of Sport Science $-2^{\text {nd }}-5^{\text {th }}$ July 2014. A. De Haan, C. J. De Ruiter, E. Tsolakidis (Eds.). Utrecht: Digital Printing Partners.

Poderys, J., Bikulčienè, L., Trinkūnas, E., Poderienė, K., Buliuolis, A., \& Vainoras, A. (2015). Matrix analysis of ECG parameters may be a way to improve quality of functional state monitoring during exercising. Baltic Journal of Sport and Health Sciences, 5, 39-45.

Römer, J., Schöllhorn, W. I., Jaitner, T., \& Preiss, R. (2009). Differenzielles Lernen im Volleyball. Sportunterricht, 58, 41-45. [Differential training in volleyball]. Physical Education, 58, 41-45.

Saltin, B., \& Rowell, L. B. (1980). Functional adaptations to physical activity and inactivity. Federation Proceedings, 39, 1506-1513.

Savelsbergh, G. J. P., Kamper, W. J., Rabius, J., De Koning, J. J., \& Schöllhorn, W. I. (2010). A new method to learn to start in speed skating: A differential learning approach. International Journal of Sports Psychology, 41, 415-427.

Schöllhorn, W. I. (2000). Applications of systems dynamic principles to technique and strength training. Acta Academiae Olympiquae Estoniae, 8, 67-85.

Schöllhorn, W. I., Beckmann, H., Janssen, D., \& Drepper, J. (2010). Stochastic perturbations in athletics field events enhance skill acquisition. In Motor Learning in Practice. A Constraints-Led Approach. London: Routledge.

Schöllhorn, W. I. (1999). Individualität - ein vernachlässigter Parameter? Leistungssport 29, 7-11. [Individuality - a neglected parameter?] Competitive Sports, 29, 7-11.

Taletavičiene, G. (2014). Changes of electrocardiographic parameters and their dynamic concatenations during whole-body cryotherapy and peloidotherapy procedures. Summary of the Doctoral Dissertation. Kaunas: Lithuanian University of Health Sciences Medical Academy.

Vainoras, A. (2002). Functional model of human organism reaction to load - evaluation of sportsman training effect. Education. Physical Training. Sport. 3, 88-93.

Wagner, H., \& Müller, E. (2008). The effects of differential and variable training on the quality parameters of a handball throw. Sports Biomechanics, 7, 54-71. doi: 10.1080/14763140701689822 